\title{
Current Procedural Terminology Coding: Do the Experts Agree?
}

\author{
Mitchell S. King, MD, Martin S. Lipsky, MD, and Lisa Sharp, PhD
}

During the past decade, the Health Care Financing Administration (HCFA) has revised the current procedural terminology (CPT) coding guidelines in an effort to clarify the work of physicians. In today's climate of health care regulation, the accuracy of how physicians use CPT coding to define their evaluation and management $(\mathrm{E} / \mathrm{M})$ services is receiving more attention. Because coding is tied to reimbursement, there is concern that financial incentives might lead to coding inaccuracies. Inaccuracies in coding, however, might also stem from the complexity of the revised coding systems rather than a financial motivation to overcode.

Ultimately a physician's coding accuracy is judged by experts who audit physician charts and examine whether the coding level reflects the documented services provided. Despite the financial and legal implications of coding appropriately, there is little research examining the agreement among expert coding specialists in their interpretation of HCFA guidelines. Previous studies have focused on physicians' coding. ${ }^{1-4}$ In this pilot study, we sought to examine the level of agreement among expert coding specialists in their evaluations of the intensity of services provided during physician office visits using the Medicare CPT E/M coding guidelines.

\section{Methods}

This study used a convenience sample of 5 expert coding specialists. These persons, representing different regions of the country, were defined as experts by Coding and Medical Information Systems of the American Medical Association. All were certified coding specialists, had at least 12 years of experience with coding, and had served as faculty in

Submitted, revised, 21 March 1999.

From the Department of Family Medicine (MSK, MSL, LS), Northwestern University Medical School, Chicago. Address reprint requests to Mitchell S. King, MD, Glenbrook Hospital, 2100 Pfingsten Road, Glenview, IL 60025.

This study was funded, in part, by the AAFP Foundation. programs designed to teach others how to code properly.

Each coding specialist was contacted by telephone, and all agreed to participate in the study. Six progress notes were created to represent the spectrum of services for outpatient visits by new or established patients. The clinical scenarios were chosen to reflect common problems encountered by family physicians. Family physician faculty at Northwestern University Medical School reviewed the progress notes for completeness and authenticity. Suggestions by the faculty were incorporated into the final versions. Each coding specialist received the six progress notes by mail accompanied by a request to assign CPT E/M codes to the cases along with the rationale for each assigned code. The results were then tabulated and reviewed for discrepancies among the coding specialists.

\section{Results}

Responses were obtained from the 5 coding specialists recruited into the study. Completed coding responses and a rationale for all the cases were returned by 4 of the 5 coding specialists. The fifth coding specialist failed to provide the rationale for one of the cases.

As shown in Table 1, a consensus in coding was obtained for only one of the six progress notes. Four coding specialists agreed on four progress notes. The final progress note was split with 3 coding specialists agreeing on one code and the remaining 2 coding specialists agreeing on the next lower code. Two of the 5 coding specialists assigned the same CPT E/M codes across all six progress notes.

Results of the individual elements for arriving at the CPT E/M code are displayed in Table 2. The three elements that are required to arrive at the correct code, namely, the history, physical examination, and the complexity of medical decision making, were individually compared for agreement in this group of expert coding specialists. As can be seen in the table, there were no instances wherein 
Table 1. Results of Health Care Financing Administration Current Procedural Terminology Evaluation and Management (CPT E/M) Codes Assigned by Expert Coding Specialists.

\begin{tabular}{|c|c|c|c|c|c|c|}
\hline $\begin{array}{l}\text { Coding } \\
\text { Specialist }\end{array}$ & Case 1 & Case 2 & Case 3 & Case 4 & Case 5 & Case 6 \\
\hline 1 & 99202 & 99213 & 99212 & 99201 & 99202 & 99214 \\
\hline 2 & 99202 & 99213 & 99212 & 99201 & 99202 & 99214 \\
\hline 3 & 99202 & 99213 & 99212 & 99201 & 99203 & 99213 \\
\hline 4 & 99202 & 99213 & 99212 & 99201 & 99202 & 99213 \\
\hline 5 & 99202 & 99214 & 99213 & 99202 & 99202 & 99214 \\
\hline
\end{tabular}

all the coding specialists agreed on any one element for any of the cases. There were four instances with three different levels assigned for the history or physical examination.

\section{Discussion}

The study results illustrate that even experts can have difficulty in interpreting and applying HCFA guidelines. Only one of the six cases was unanimously coded at the same level. Despite the lack of agreement in the final coding for all cases, however, all the codes were within one level of each other, and five of the six cases had nearly unanimous $(80 \%$ to $100 \%$ ) agreement.

The elements used to support decisions about coding for physician services are the history, physical examination, and the complexity of medical decision making. Interestingly, although the coding specialists were relatively similar in their final CPT $\mathrm{E} / \mathrm{M}$ code, there were marked differences in opinion in interpreting the individual elements used to support the applied code. In some instances, there were three different levels assigned for the history or physical examination despite an overall agreement in the final code. This finding suggests that even experts might use an overall sense or gestalt about the intensity of service to arrive at a given level of service. An example is shown in Table 3 (case 1 from Table 1), wherein all coding specialists agreed on the final CPT E/M code but were quite different in their rationale for arriving at this code.

One reason for differences in expert opinion could be related to the subjectivity involved in interpreting the guidelines. For example, an element of the history could be interpreted as an associated sign or symptom as opposed to a review of system. This interpretation could result in a different final assigned CPT E/M code. Additionally, the decision of whether a problem is "selflimited or minor" or a "new problem, no further work-up planned" will affect the complexity of medical decision-making element and the final CPT E/M code. These subjective elements are woven into the complex set of guidelines and are

Table 2. Results of Individual Elements to Arrive at CPT E/M Codes Assigned by Expert Coding Specialists.

\begin{tabular}{llllllllllllll}
\hline Elements & \multicolumn{1}{c}{ Case 1 } & \multicolumn{2}{c}{ Case 2 } & \multicolumn{2}{c}{ Case 3 } & \multicolumn{2}{c}{ Case 4 } & \multicolumn{2}{c}{ Case 5 } & \multicolumn{2}{c}{ Case 6 } \\
\hline History & PF & 1 & EPF & 3 & PF & 3 & PF & 3 & EPF & 1 & EPF & 2 \\
& EPF & 2 & D & 2 & EPF & 1 & D & 2 & D & 2 & D & 3 \\
& C & 2 & & & NR & 1 & & & C & 2 & & \\
Physical examination & PF & 1 & PF & 1 & PF & 2 & PF & 3 & EPF & 4 & EPF & 1 \\
& EPF & 4 & EPF & 3 & EPF & 2 & EPF & 2 & D & 1 & D & 3 \\
& & & D & 1 & NR & 1 & & & & & C & 1 \\
$\begin{array}{l}\text { Complexity of medical } \\
\text { decision making }\end{array}$ & S & 2 & LC & 2 & S & 2 & S & 3 & LC & 2 & LC & 1 \\
& MC & 3 & MC & 3 & LC & 2 & LC & 2 & MC & 3 & MC & 4 \\
& & & & & NR & 1 & & & & & & \\
\hline
\end{tabular}

CPT E/M = Health Care Financing Administration current procedural terminology-evaluation and management, $\mathrm{PF}=$ problem focused, $\mathrm{EPF}=$ expanded problem focused, $\mathrm{D}=$ detailed, $\mathrm{C}=$ comprehensive, $\mathrm{S}=$ straightforward, $\mathrm{LC}=$ low complexity, $\mathrm{MC}=$ moderate complexity, $\mathrm{NR}=$ no response. 
Table 3. Analysis of Case 1 From Table 1: Consensus Coding at 99202.

\begin{tabular}{clcc}
\hline $\begin{array}{l}\text { Coding } \\
\text { Specialist }\end{array}$ & History & $\begin{array}{c}\text { Physical } \\
\text { Examination }\end{array}$ & $\begin{array}{c}\text { Medical Decision } \\
\text { Making }\end{array}$ \\
\hline 1 & EPF & EPF & S \\
2 & C & EPF & MC \\
3 & PF & EPF & S \\
4 & EPF & PF & MC \\
5 & C & EPF & MC \\
\hline
\end{tabular}

EPF = expanded problem focused, $\mathbf{S}=$ straightforward, $\mathbf{C}=$ comprehensive, $\mathrm{MC}=$ moderate complexity, $\mathrm{PF}=$ problem focused.

open to interpretation by the person performing the coding.

Another reason that could account for differences in the experts' codes is that there are two sets of CPT E/M guidelines in use. The experts in the study were not told to use one or the other, but to use the guidelines of their choice, because this choice mimics the reality that physicians currently experience. The experts did not all use the same guidelines, as evidenced by notes written about the progress notes they reviewed. Even those that used the same guidelines, however, arrived at different codes in several instances. In addition, the differences between the two sets of guidelines would only account for differences in the physical examination element and would not account for the discrepancies seen in the other elements.
Although the number of experts sampled in the study is small, the results suggest that a reference standard for auditing charts using existent guidelines might be difficult to develop and is subject to individual interpretation. Coding guidelines should be able to yield results that are almost identical when applied by different persons. This consistency is critical, since an accusation that a physician is coding improperly can lead to fraud and abuse charges. Further examination is warranted to confirm the results of this study and to help define a normal error rate. In addition to confirming the findings reported here, additional study might provide insight into the coding process that could improve this tedious but necessary aspect of clinical practice.

\section{References}

1. Chao J, Gillanders WG, Flocke SA, Goodwin MA, Kikano GE, Stange KC. Billing for physician services: a comparison of actual billing with $\mathrm{CPT}$ codes assigned by direct observation. J Fam Pract 1998;47: 28-32.

2. Purvis JR, Horner RD. Billing practices of North Carolina family physicians. J Fam Pract 1991;32: 487-91.

3. Horner RD, Paris JA, Purvis JR, Lawler FH. Accuracy of patient encounter and billing information in ambulatory care. J Fam Pract 1991;33:593-8.

4. Lawler FH, Purvis JR, Paris JA, Horner RD. The effect of faculty private practice experience on appropriate charging for professional services. Fam Med 1990;22:487-9. 